\title{
No-touch aorta off-pump coronary surgery: The effect on stroke
}

\author{
Oren Lev-Ran, MD \\ Rony Braunstein, $\mathrm{PhD}^{\mathrm{b}}$ \\ Ram Sharony, MD \\ Amir Kramer, $\mathrm{MD}^{\mathrm{a}}$ \\ Yosef Paz, MD \\ Rephael Mohr, MDa \\ Gideon Uretzky, MDa
}

From the Department of Cardiothoracic Surgery, Tel Aviv Sourasky Medical Center, Tel Aviv, Israel, ${ }^{a}$ and the Department of Epidemiology, Sackler Faculty of Medicine, Tel Aviv University, Tel Aviv, Israel. ${ }^{\text {b }}$

Received for publication March 24, 2004; revisions received May 21, 2004; accepted for publication June 4, 2004.

Address for reprints: Oren Lev-Ran, MD, Department of Cardiothoracic Surgery, The Tel Aviv Sourasky Medical Center, 6 Weizmann St, Tel Aviv 64239, Israel (Email: orenlevran@hotmail.com).

J Thorac Cardiovasc Surg 2005;129:307-13 $0022-5223 / \$ 30.00$

Copyright $(9) 2005$ by The American Association for Thoracic Surgery

doi:10.1016/j.jtcvs.2004.06.013
Objective: Studies examining the neuroprotective effects of off-pump coronary artery bypass grafting have shown inconsistent results. Most studies, however, have not differentiated between clampless and clamp off-pump techniques. The aim of this study was to evaluate the effect of avoiding aortic manipulation on major neurologic outcomes after off-pump coronary artery bypass grafting.

Methods: A total of 700 consecutive patients undergoing multiple-vessel off-pump coronary artery bypass grafting between 2000 and 2003 were included. The 429 patients undergoing aortic no-touch technique were compared with 271 patients in whom partial aortic clamps were applied. The aorta was screened by manual palpation, and epiaortic ultrasonography was used selectively.

Results: The frequency of detected atherosclerotic aortic disease was higher in the no-touch group $(17.4 \%$ vs $5.1 \%, P<.0001)$. No-touch revascularization was achieved with arterial conduits, arranged in T-graft or in situ configurations (50\%). The respective graft/patient ratios were $2.5 \pm 0.6$ and $2.6 \pm 0.6$ in the side-clamp and no-touch groups $(P=.009)$; however, revascularization of the posterolateral myocardial territory was comparable ( $87 \%$ vs $90 \%$, difference not significant). The incidence of stroke $(0.2 \%$ vs $2.2 \%, P=.01)$ was significantly lower in the no-touch group (1/429). Logistic regression identified partial aortic clamping as the only independent predictor of stroke (odds ratio 28.5, confidence interval 0.22-333, $P=$ $.009)$, increasing this risk 28 -fold. Peripheral vascular disease $(P=.068)$, diabetes $(P=.072)$, and history of stroke $(P=.074)$ trended toward stroke.

Conclusions: Avoiding partial aortic clamping during off-pump coronary artery bypass grafting provides superior neurologic outcome. The results are reproducible and irrespective of the severity of aortic disease or the method of aortic screening. This technique is recommended whenever technically feasible.

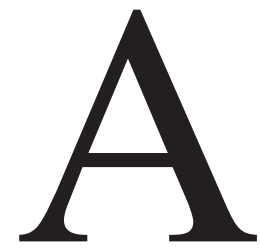

lthough the death rates associated with cardiac operations have declined during the past decade, neurologic complications remain a substantial source of morbidity and mortality. ${ }^{1}$ Explanations for this finding have focused on changing risk profiles in patient age, coexisting diseases, and diagnostic test use. ${ }^{1}$

Embolic dislodgment of atherosclerotic plaques during surgical aortic manipulations has been recognized as a major cause of stroke. ${ }^{2,3}$ Coronary artery bypass grafting ( $\mathrm{CABG}$ ) done without $\mathrm{CPB}$ (off-pump CABG [OPCAB]) eliminates the risk of atheroemboli associated with aortic cannulation, crossclamping, and pump-related platelet aggregate emboli. ${ }^{4}$ Although it has been reported that the risk of stroke is lowered by $\mathrm{OPCAB},{ }^{5,6}$ this benefit has been inconsistently 
demonstrated ${ }^{7,8}$ and was not reproduced in a randomized study. ${ }^{9-11}$ Most studies, however, have not differentiated between OPCAB strategies with partial aortic clamps for the construction of proximal aortic anastomoses and those in which revascularization was performed without aortic manipulation (no-touch technique). ${ }^{6-11}$ Compelling data have shown that the placement and removal of these clamps are linked to cerebral embolic load ${ }^{12}$ and thus the risk of embolic stroke. Interestingly, studies evaluating the effect of partial aortic clamping and, reciprocally, the neurologic benefit in avoiding aortic manipulation have yielded contradictory results. ${ }^{5,13}$ Subgroup analysis by Calafiore and colleagues ${ }^{13}$ determined the subsequent risk of stroke, suggesting that it compares to the risk after total aortic manipulations required for on-pump CABG. Conversely, Patel and coworkers ${ }^{5}$ have proposed that avoiding aortic manipulation during OPCAB is not associated with improved neurologic outcome. Thus the superiority of any OPCAB technique in terms of major neurologic outcome in unselected patients remains undetermined.

The use of arterial in situ or $\mathrm{T}$ configurations during OPCAB allow clampless revascularization without any aortic manipulation (aortic no-touch). ${ }^{5,14}$ The purpose of this study was to compare major neurologic outcomes after aortic no-touch versus side-clamp OPCAB techniques in the general population. To avoid preselection for either OPCAB or on-pump CABG and subsequent potential bias in patient allocation, we limited our study cohort exclusively to patients undergoing $\mathrm{OPCAB}$.

\section{Patients and Methods Study Design}

The data from 700 consecutive patients who underwent isolated OPCAB with multiple grafts between September 2000 and September 2003 were acquired. The 471 patients who were operated on without aortic manipulation (no-touch group) were compared with the 229 patients in whom partial aortic clamps were applied during the construction of proximal aortic anastomoses (sideclamp group). OPCAB procedures comprised $60 \%$ of the isolated $\mathrm{CABG}$ operations performed during this period, and arterial revascularization was applied in $75 \%$ of the patients.

Patients who underwent minimally invasive direct $\mathrm{CABG}$ and those undergoing midsternotomy single graft anterior wall revascularizations by in situ left internal thoracic artery (ITA) were not included, to avoid preselection for the no-touch group. Proximal mechanical connectors or clampless suture-based proximal devices were not used in any of the patients.

The aorta was routinely screened by digital palpation. The degree of aortic disease was graded in accordance with the criteria of Mills and Everson. ${ }^{15}$ When this was graded as none or mild (areas free of aortic disease easily identified), the patient was considered eligible for both techniques and patient allocation was based on technical considerations. ${ }^{16}$ No-touch OPCAB was favored when the extent of aortic disease was graded as moderate (disease moderately extensive but with adequate disease-free ar- eas) or severe (circumferential disease with no disease-free areas). Thus by definition the prevalence and severity of aortic disease were higher in the no-touch group.

Epiaortic ultrasonography was performed selectively. A 7.5MHz probe (Hewlett-Packard Company, Palo Alto, Calif) was used when undetermined findings were encountered during digital aortic palpation or when a high index of suspicion arose after chest radiography or coronary angiography. The ultrasonographic findings were evaluated by the surgeon himself.

All patients were routinely screened by carotid Doppler assessments. The patients who required carotid endarterectomy (symptoms with unilateral stenosis $>70 \%$ or symptoms with severe bilateral stenosis) were excluded from this study.

\section{Definition of Terms}

Patients' data were collected and analyzed according to the Society of Thoracic Surgeons National Cardiac Surgery database guidelines and definitions (http://www.ctsnet.org/doc/4314). Operative mortality was defined as death occurring within 30 days of the operation. Neurologic complications were defined as any global or focal neurologic deficit that was evident after emergence from anesthesia and categorized as either permanent or reversible (transient ischemic attacks and prolonged reversible ischemic neurologic deficit). All neurologic events were evaluated by a neurologist and further assessed by computed tomographic scan.

\section{Surgical Technique and Postoperative Management}

Operations were performed through midline sternotomy. Anticoagulation was achieved with $2 \mathrm{mg} / \mathrm{kg}$ heparin, and the activated clotting time was maintained above 300 seconds. The heart was stabilized with a suction tissue stabilization system (Octopus; Medtronic, Inc, Minneapolis, Minn). A deep pericardial retraction suture was placed at the posterior fibrous pericardium medial to the proximal part of the inferior vena cava to help manipulate and rotate the heart to vertical and lateral positions. A right-sided pericardial incision directed toward the inferior vena cava was selectively performed to facilitate venous return. Vessel occlusion was achieved by external encircling silicone rubber bands. Intracoronary shunts were used occasionally.

Grafting in the no-touch group was composed of arterial conduits only. These included the left and right ITAs, the radial artery (RA), and the right gastroepiploic artery (RGEA). The grafts were deployed as left-sided in situ bilateral ITA or T configurations constructed of bilateral ITA or left ITA-RA. The ITAs were routinely skeletonized, ${ }^{16}$ and dissection of the RA and the RGEA was facilitated by ultrasonic scalpel (Harmonic Scalpel; Ethicon Endosurgery, Cincinnati Ohio). The choice of configuration was determined by technical considerations related to the conduits, as has been previously described for conventional on-pump CABG. ${ }^{15}$ When $\mathrm{T}$ grafts were used, $\mathrm{T}$ anastomoses were constructed before the distal coronary anastomoses. The RGEA was always used as in situ graft.

Revascularization in the side-clamp group was achieved with ITAs and saphenous vein grafts. All saphenous vein grafts were attached to the aorta and constructed proximally after placement of partial aortic clamp. Anterior wall revascularization was routinely performed first in the sequence of grafting in both groups.

After the operation, all patients received intravenously administered isosorbide dinitrate $(4-20 \mathrm{mg} / \mathrm{h})$ for 2 days. Oral calcium- 
TABLE 1. Preoperative characteristics

\begin{tabular}{|c|c|c|c|}
\hline Variable & $\begin{array}{l}\text { No-touch group } \\
(\mathrm{n}=429)\end{array}$ & $\begin{array}{l}\text { Side-clamp group } \\
(\mathrm{n}=271)\end{array}$ & $P$ value \\
\hline Age (y) & & & .235 \\
\hline Mean & $67.4 \pm 11.5$ & $68.4 \pm 10.9$ & \\
\hline Range & $33-94$ & $40-92$ & \\
\hline Age $\geq 80$ y (No.) & $56(13.1 \%)$ & $27(10.0 \%)$ & .233 \\
\hline Female (No.) & $117(27.3 \%)$ & $81(30.0 \%)$ & .436 \\
\hline Hypertension (No.) & $283(66.0 \%)$ & $166(61.7 \%)$ & .253 \\
\hline Diabetes (No.) & $169(39.4 \%)$ & $108(40.0 \%)$ & .873 \\
\hline Peripheral vascular disease (No.) & $74(17.3 \%)$ & $39(14.4 \%)$ & .304 \\
\hline Creatinine $>2 \mathrm{mg} / \mathrm{dL}$ (No.) & $25(5.8 \%)$ & $35(13 \%)$ & .001 \\
\hline Chronic lung disease (No.) & $38(8.9 \%)$ & $24(8.9 \%)$ & .999 \\
\hline Acute myocardial infarction $<1$ wk (No.) & $44(10.3 \%)$ & $19(7 \%)$ & .144 \\
\hline Congestive heart failure (No.) & $68(15.9 \%)$ & $47(17.4 \%)$ & .589 \\
\hline Left main stenosis $>50 \%$ (No.) & $120(28.2 \%)$ & $79(29.3 \%)$ & .756 \\
\hline Three-vessel disease (No.) & $399(93 \%)$ & $254(93.7 \%)$ & .710 \\
\hline Ejection fraction $\leq 35 \%$ (No.) & $33(7.7 \%)$ & $21(7.7 \%)$ & .992 \\
\hline Emergency operation (No.) & $28(6.5 \%)$ & $21(7.8 \%)$ & .528 \\
\hline Preoperative intra-aortic balloon pump (No.) & $26(6.1 \%)$ & $16(5.9 \%)$ & .932 \\
\hline Previous cerebrovascular disease (No.) & $41(9.6 \%)$ & $23(8.5 \%)$ & .632 \\
\hline \multicolumn{4}{|l|}{ Carotid disease (No.) } \\
\hline Moderate (50\%-70\% stenosis) & $67(15.6 \%)$ & $54(19.9 \%)$ & .142 \\
\hline Severe (>70\% stenosis) & $10(2.3 \%)$ & $8(2.9 \%)$ & .613 \\
\hline
\end{tabular}

channel blockers (Dilatam; Teva, Petah-Tikva, Israel) were given to patients who received RA or RGEA conduits and continued for 6 months. Antiplatelet therapy included aspirin at $250 \mathrm{mg} / \mathrm{d}$ (recommended for indefinite use) and clopidogrel at $75 \mathrm{mg} / \mathrm{d}$ (Plavix; Sanofi Winthrop, Gentilly, France) for 6 postoperative weeks.

\section{Data Analysis}

The categoric variables were tested for group independence with the $\chi^{2}$ test. The results are expressed as the percentages and $P$ value. Numeric variables were compared with both the $t$ test and the nonparametric Mann-Whitney test. Data are expressed as mean $\pm \mathrm{SD}$ with $P$ value. Logistic regression was used to evaluate the effect of preoperative and intraoperative descriptors on occurrence of neurologic complications, early death, and the combined end point of stroke or death. Results of logistic regression were expressed as odds ratio (OR) with associated $95 \%$ confidence interval (CI) and $P$ values. All analyses were performed with SPSS 11 software (SPSS Inc, Chicago, Ill).

\section{Results}

The baseline characteristics among the two groups were comparable, with the exception of a higher prevalence of renal dysfunction in the side-clamp group (Table 1). Operative data are listed in Table 2 . The no-touch technique was performed in $61 \%$ of the cases. The prevalence and severity of aortic disease were greater in the no-touch group. Moderate to severe atheromatous involvement was detected in $16.5 \%$ of these patients, whereas all but 3 patients $(1 \%)$ in the side-clamp group were free of involvement or had only mild involvement $(P<.0001)$. Despite a higher mean number grafts in the side-clamp group $(2.5 \pm 0.6$ vs $2.6 \pm$
$0.6, P=.009$ ), revascularization of the posterolateral territory (the distribution of obtuse marginals or posterior descending arteries) was comparable (Table 2).

\section{Operative Mortality and Morbidity}

Early mortality was lower in the no-touch group, although the difference did not reach statistical significance (Table 3). The EuroSCORE-predicted mortalities were $4.8 \% \pm 8 \%(95 \% \mathrm{CI}$ $0.055-0.073)$ and $4.3 \% \pm 6 \%$ (95\% CI $0.049-0.054)$ in the no-touch and side-clamp groups, respectively $(P=.326)$. The modes of death were cardiac-related (5 patients), sepsis (4 patients), acute abdominal ischemia (3 patients, of whom acute mesenteric event was diagnosed during laparotomy in 2), and acute aortic dissection (1 patient).

The incidence of major neurologic complications was significantly higher in the side-clamp group (1/429 or $0.2 \%$ vs $2.2 \%$ or $6 / 271, P=.01$; Table 3 ). The types and distribution of neurologic deficits were as follows: permanent (stroke) in 5 patients and prolonged reversible ischemic neurologic deficit in 2 patients, in the right cerebral hemisphere in 4 patients and the left cerebral hemisphere in 3 patients. Two patients who had strokes had been regarded by the surgeon as being free of aortic disease, and in 3 patients with stroke the aorta was considered mildly involved.

\section{Prediction of Neurologic Complications and Mortality}

The surgical technique including use of partial aortic clamp (OR 28.5, 95\% CI 0.22-333, $P=.009$,) was identified as independent predictor for neurologic complications. Periph- 
TABLE 2. Operative data

\begin{tabular}{|c|c|c|c|}
\hline Variable & $\begin{array}{l}\text { No-touch group } \\
(n=429)\end{array}$ & $\begin{array}{l}\text { Side-clamp group } \\
\quad(\mathrm{n}=271)\end{array}$ & $P$ value \\
\hline Epiaortic ultrasonography (No.) & $21(4.8 \%)$ & $52(19 \%)$ & $<.0001$ \\
\hline Grafts/patient & & & .009 \\
\hline Mean & $2.5 \pm 0.6$ & $2.6 \pm 0.6$ & \\
\hline Range & $2-4$ & $2-5$ & \\
\hline Atherosclerotic aorta (No.) & $75(17.4 \%)$ & $14(5.1 \%)$ & $<.0001$ \\
\hline \multicolumn{4}{|l|}{ Aortic grading (No.) } \\
\hline Moderate atherosclerosis & $45(10.4 \%)$ & $3(1.1 \%)$ & $<.0001$ \\
\hline Severe atherosclerosis & $26(6.1 \%)$ & $0(0 \%)$ & .0009 \\
\hline Use of left ITA (No.) & $427(99.5 \%)$ & $269(99.2 \%)$ & .642 \\
\hline Use of right ITA (No.) & $245(57.1 \%)$ & $83(30.6 \%)$ & $<.0001$ \\
\hline Use of bilateral ITA (No.) & $236(55.3 \%)$ & $83(30.6 \%)$ & $<.0001$ \\
\hline Use of RA (No.) & $174(40 \%)$ & $8(2.9 \%)$ & $<.0001$ \\
\hline Use of RGEA (No.) & $27(6.3 \%)$ & $1(0.4 \%)$ & $<.0001$ \\
\hline Use of saphenous vein graft (No.) & $5(1.2 \%)$ & $261(96.7 \%)$ & $<.0001$ \\
\hline T grafts (No.) & $213(49.7 \%)$ & $30(11.1 \%)$ & $<.0001$ \\
\hline Sequential grafting (No.) & $155(36.2 \%)$ & $28(10.3 \%)$ & $<.0001$ \\
\hline Bilateral ITA cross configuration (No.) & $146(34 \%)$ & $58(21.4 \%)$ & $<.0001$ \\
\hline Grafts to posterolateral territory (No.) & $388(90.4 \%)$ & $236(87.1 \%)$ & 164 \\
\hline \multicolumn{4}{|l|}{ Target coronary vessel (No.) } \\
\hline Left anterior descending & $429(40 \%)$ & $271(40 \%)$ & \\
\hline Diagonal & $101(9.4 \%)$ & $58(8.6 \%)$ & .510 \\
\hline Circumflex & $354(33.4 \%)$ & $156(23 \%)$ & $<.0001$ \\
\hline Right & $31(2.8 \%)$ & $34(5 \%)$ & .182 \\
\hline Posterior descending & $157(14.6 \%)$ & $158(23.3 \%)$ & $<.0001$ \\
\hline
\end{tabular}

TABLE 3. Early results

\begin{tabular}{|c|c|c|c|c|}
\hline Variable & $\begin{array}{l}\text { No-touch group } \\
(\mathrm{n}=429)\end{array}$ & $\begin{array}{l}\text { Side-clamp group } \\
\qquad(\mathrm{n}=271)\end{array}$ & $\begin{array}{c}\text { Total } \\
(\mathrm{n}=700)\end{array}$ & $P$ value \\
\hline Hospital stay (d) & & & & 166 \\
\hline Mean \pm SD & $5.5 \pm 4.2$ & $5.9 \pm 3.6$ & $5.7 \pm 4$ & \\
\hline Range & $0-20$ & $0-24$ & $0-24$ & \\
\hline Early death (No.) & $9(2.1 \%)$ & $7(2.6 \%)$ & $16(2.3 \%)$ & 679 \\
\hline Myocardial infarction (No.) & $6(1.4 \%)$ & $4(1.5 \%)$ & $10(1.5 \%)$ & .936 \\
\hline Atrial fibrillation (No.) & $62(14.8 \%)$ & $39(14.8 \%)$ & $101(14.8 \%)$ & .991 \\
\hline Re-exploration for bleeding (№.) & $5(1.2 \%)$ & $5(1.9 \%)$ & $10(1.5 \%)$ & .448 \\
\hline Renal failure* (No.) & $16(3.8 \%)$ & $16(6.0 \%)$ & $32(4.7 \%)$ & .166 \\
\hline \multicolumn{5}{|l|}{ Sternal infection (No.) } \\
\hline Deep & $4(0.9 \%)$ & $1(0.4 \%)$ & $5(0.7 \%)$ & .388 \\
\hline Superficial & $10(2.3 \%)$ & $15(5.5 \%)$ & $25(3 \%)$ & .026 \\
\hline Major neurologic event (No.) & $1(0.2 \%)$ & $6(2.2 \%)$ & $7(1.0 \%)$ & .010 \\
\hline Neurologic event or death (No.) & $10(2.4 \%)$ & $13(4.9 \%)$ & $23(3.3 \%)$ & .072 \\
\hline
\end{tabular}

*Defined as serum creatinine level $2 \mathrm{mg} / \mathrm{dL}$ or more, or postoperative increase of $1 \mathrm{mg} / \mathrm{dL}$.

eral vascular disease $(P=.068)$, history of cerebrovascular disease $(P=.074)$, and diabetes $(P=.072)$ tended to predict neurologic complications (Table 4). Emergency operation (OR 8.7, 95\% CI 1.99-38.3, $P=.004$ ) and renal dysfunction (OR 11.5, 95\% CI 3.02-43.8, $P<.0001$ ) were identified as correlates of mortality (Table 4 ). The use of partial aortic clamping tended to predict the occurrence of neurologic complications or mortality (OR 2.55, 95\% CI 0.96-6.75, $P=.060$ ).

\section{Discussion}

The findings of this study suggest that avoiding partial aortic clamping enhances the neuroprotective effect of $\mathrm{OPCAB}$. This benefit was reproducible and attained irre- 
TABLE 4. Logistic regression: Independent risk factors for stroke, death, and combined outcome of stroke or death

\begin{tabular}{|c|c|c|c|c|c|c|c|c|c|}
\hline \multirow[b]{2}{*}{ Variable } & \multicolumn{3}{|c|}{ Stroke } & \multicolumn{3}{|c|}{ Death } & \multicolumn{3}{|c|}{ Stroke or death } \\
\hline & OR & $95 \% \mathrm{Cl}$ & $P$ value & OR & $95 \% \mathrm{Cl}$ & $P$ value & $\mathbf{O R}$ & $95 \% \mathrm{Cl}$ & $P$ value \\
\hline Age & 1.05 & $0.93-1.18$ & .397 & 1.06 & $0.99-1.15$ & .081 & 1.06 & $1.00-1.13$ & .039 \\
\hline Sex & 6.65 & $0.60-73.5$ & .122 & 0.51 & $0.14-1.82$ & .303 & 0.95 & $0.33-2.72$ & .929 \\
\hline Diabetes & 6.89 & $0.60-56.6$ & .072 & 0.92 & $0.26-3.23$ & .903 & 1.38 & $1.00-3.77$ & .520 \\
\hline Hypertension & - & - & - & 1.40 & $0.36-5.47$ & .621 & 2.21 & $0.66-7.43$ & .197 \\
\hline Peripheral vascular disease & 6.16 & $0.87-43.5$ & .680 & 1.26 & $0.32-4.95$ & .731 & 1.87 & $0.64-5.37$ & .244 \\
\hline Renal failure & 1.19 & $0.04-31.3$ & .913 & 11.5 & $3.02-43.8$ & $<.0001$ & 7.55 & $2.39-23.8$ & .001 \\
\hline Chronic lung disease & 0 & $0.00-5.40$ & .943 & - & - & - & - & - & - \\
\hline Cerebrovascular disease & 5.56 & $0.84-36.4$ & .074 & 2.06 & $0.36-11.7$ & .412 & 2.77 & $0.81-9.45$ & .102 \\
\hline Atrial fibrillation & 0 & $0.00-1.30$ & .926 & 1.3 & $0.22-7.47$ & .762 & 0.77 & $0.15-3.95$ & .761 \\
\hline Congestive heart failure & 1.59 & $0.13-19.1$ & .712 & 1.1 & $0.20-5.83$ & .906 & 1.04 & $0.27-4.02$ & .947 \\
\hline Left main disease & 3.86 & $0.68-21.7$ & .126 & 0.41 & $0.10-1.62$ & .208 & 0.94 & $0.34-2.57$ & .913 \\
\hline Emergency operation & 0 & $0.00-1.40$ & .931 & 8.74 & $1.99-38.3$ & .004 & 3.81 & $1.02-14.1$ & .045 \\
\hline \multicolumn{10}{|l|}{ Operative variables } \\
\hline Use of bilateral ITA & 2.52 & $0.38-16.7$ & .338 & 2.24 & $0.63-7.89$ & .209 & 2.06 & $0.75-5.65$ & .157 \\
\hline Use of side-clamp & 28.5 & $2.27-333.3$ & .009 & 1.04 & $0.30-3.55$ & .939 & 2.55 & $0.96-6.75$ & .600 \\
\hline
\end{tabular}

spective of the severity of aortic disease or the method of aortic screening. It has been shown that the no-touch technique can be implemented in most OPCAB procedures and that routine use of arterial conduits for this purpose is feasible.

Refinements in surgical techniques and the advent of tissue stabilizers have markedly reduced blood pressure fluctuations and the subsequent risk of stroke during offpump displacement of the beating heart. ${ }^{17}$ Partial aortic clamping, however, remains a potential cause for embolic stroke during OPCAB. Post-OPCAB stroke rates ranging from $0 \%$ to $3.3 \%$ have been reported..$^{5-11,14,17-19}$ This wide range may reflect differences in patient profiles but may also stem from different operative strategies, such as the choice of graft deployment and aortic screening methods.

In this study, the low $1 \%$ overall incidence of major neurologic complications stemmed from the differential effect of the no-touch technique. There was 1 neurologic event among the 429 consecutive patients in the no-touch OPCAB group $(0.2 \%)$. To date, data on the benefit of avoiding partial aortic clamps during OPCAB are sparse; however, our results validate previous reports of low stroke rates in corresponding no-touch OPCAB subgroups $\left(0.5 \%,{ }^{5}\right.$ $0.4 \%^{14}$ and $0 \%{ }^{20,21}$ ). This consistent reduction in the incidence of stroke below $1 \%$ may reflect on the reproducibility of the no-touch technique. Our results should be viewed in with respect to the relatively old age of the patient cohort (Table 1). Preoperative risk factors of stroke-history of cerebrovascular disease, ${ }^{22}$ peripheral vascular disease, ${ }^{23}$ diabetes, ${ }^{23}$ and hypertension, ${ }^{24}$ and carotid disease-were evenly distributed between the groups. After adjustment for confounding factors, the use of partial aortic clamping was found to be the only independent predictor of stroke, in- creasing this risk 28 -fold. Consistent with previous observations, ${ }^{22,23}$ history of cerebrovascular disease, peripheral vascular disease, and diabetes tended to predict stroke.

The 2.2\% neurologic event rate observed our side-clamp group is compatible with stroke rates reported after previous OPCAB series..$^{5-11,14,17-19}$ In our study, as well as in previous studies of corresponding subgroups, it is likely that certain cases of atherosclerotic aortic disease were undetected and resulted in stroke. Epiaortic ultrasonography has been established as the modality of choice for aortic screening, ${ }^{25}$ with manual palpation linked to a higher frequency of underdetection. It is apparent that in this study a suboptimal detection rate was achieved (Table 2), because the reported frequency of significantly atheromatous aorta detected in epiaortic ultrasonographic studies ranges from $21 \%$ to $62 \%{ }^{25,26}$ Epiaortic ultrasonography during OPCAB has been reported to be useful in making the decision to deploy grafts on the ascending aorta and in making adjustments in the location of side-clamps once ultrasonographic findings have been detected. ${ }^{27}$ This, however, remains a problem considering that the frequency of atherosclerotic anterior wall aortic findings that indicate surgical modifications may reach $35 \%$, and in $25 \%$ of patients undergoing $\mathrm{OPCAB}$, revascularization without aortic manipulation may be eventually required. ${ }^{27}$ Despite the efficacy of epiaortic ultrasonography, ${ }^{25-27}$ not all strokes may be prevented by it. The decisions concerning surgical modifications are made on the basis of qualitative ultrasonographic information and are usually based on the surgeon's evaluation; thus the potential for errors is not obviated. The wide range of ultrasonographic detection rates $(21 \%-62 \%)$ is a cause of concern, ${ }^{25,26}$ and a major limitation is the fact that ultrasonography is not always available. At the time of our study 
routine, epiaortic ultrasonography was not considered to be the standard of care and was reserved for select high-risk patients. This policy has been apparently applied by many other centers as well. ${ }^{6}$ Mechanical or suture-based clampless proximal connectors are other options that have been contemplated for reducing the risk of atheroembolism during OPCAB while allowing some degree of aortic manipulation. ${ }^{28}$ Several concerns, however, have recently been raised. Embolic particulate debris after the use of anastomotic devices is still evident, ${ }^{29}$ and the safety of these devices remains unresolved after reports of device-related early graft closure. ${ }^{30}$ No-touch OPCAB may therefore be still the modification of choice once aortic disease has been ultrasonographically detected.

In this study, the term "no-touch grafting" denotes total arterial revascularization. The literature does not offer a clear mandate for routine composite attachment of venous grafts. Despite several exceptions to this rule, ${ }^{19}$ arterial conduits, arranged in composite or in situ configurations, are usually required for this purpose. ${ }^{5,16,20}$ Our results demonstrate that this strategy can be implemented for most patients undergoing OPCAB.

Several limitations of this study need to be addressed. Under the assumption that failure to detect atherosclerotic aortic plaques resulted in stroke, a comparative study with systematic epiaortic ultrasonography for all patients is warranted. This study is restricted in the ability to detect multiple predictors of neurologic events because only 7 such events occurred in this series. In addition, a comparative prospective randomized trial is required to validate our results. The reproducible results conferred by the no-touch technique, however, remain indisputable. We could not differentiate between the effect of single versus multiple aortic side-clamps on stroke. Relevant issues for further assessment would be the role of newly available clampless proximal anastomotic devices and the effect of no-touch OPCAB on neurocognitive outcomes.

In conclusion, the aortic no-touch OPCAB technique provides superior neurologic outcome irrespective of the aortic screening strategy or the severity of atherosclerotic disease. This technique should be considered whenever technically feasible.

\section{References}

1. Ferguson TB Jr, Hammil BG, Peterson ED, DeLong ER, Grover FL, STS National Database Committee. A decade of change-risk profiles and outcomes for isolated coronary artery bypass grafting procedures, 1990-1999: a report from the STS National Database Committee and the Duke Clinical Research Institute. Society of Thoracic Surgeons. Ann Thorac Surg. 2002;73:480-9.

2. Roach GW, Kanchuger M, Mangano CM, Newman M, Nussmeier N, Wolman R, et al. Adverse cerebral outcomes after coronary bypass surgery. Multicenter Study of Perioperative Ischemia Research Group and the Ischemia Research and Education Foundation Investigators. N Engl J Med. 1996;335:1857-63.
3. Barbut D, Yao FF, Lo YW, Silverman R, Hager DN, Trifiletti RR, et al. Determination of size of aortic emboli and embolic load during coronary artery bypass. Ann Thorac Surg. 1997;63:1262-7.

4. Matata BM, Sosonowski AW, Galinanes M. Off-pump bypass graft operation significantly reduces oxidative stress and inflammation. Ann Thorac Surg. 2000;69:785-91.

5. Patel NC, Deodhar AP, Grayson AD, Pullan DM, Keenan DJ, Hasan R, et al. Neurological outcome in coronary surgery: independent effect of avoiding cardiopulmonary bypass. Ann Thorac Surg. 2002;74:400-6.

6. Stamou SC, Jablonski KA, Pfister AJ, Hill PC, Dullum MK, Bafi AS, et al. Stroke after conventional versus minimally invasive coronary artery bypass. Ann Thorac Surg. 2002;74:394-9.

7. Cheng W, Denton TA, Fontana GP, Raissi S, Blanche C, Kass RM, et al. Off-pump coronary surgery: Effect on early mortality and stroke. J Thorac Cardiovasc Surg. 2002;124:313-20.

8. Sabik JD, Gillinov AM, Blackstone EH, Vacha C, Houghtaling PL, Navia J, et al. Does off-pump coronary surgery reduce morbidity and mortality? J Thorac Cardiovasc Surg. 2002;124:698-707.

9. Puskas JD, Williams WH, Duke PG, Stapels JR, Glas KE, Marshall JJ, et al. Off-pump coronary artery bypass grafting provides complete revascularization with reduced myocardial injury, transfusion requirements and length of stay: a prospective randomized comparison of two hundred unselected patients undergoing off-pump versus conventional coronary artery bypass grafting. J Thorac Cardiovasc Surg. 2003;125:797-808.

10. Angelini GD, Taylor FC, Reeves BC, Ascione R. Early and mid-term outcome after off-pump and on-pump surgery in Beating Heart Against Cardioplegic Arrest Studies (BHACAS 1 and 2): a pooled analysis of two randomised controlled trials. Lancet. 2002;359:1194-9.

11. van Dijk D, Nierich AP, Jansen EW, Nathoe HM, Suyker WJ, Diephuis JC, et al. Early outcome after off-pump versus on-pump coronary artery bypass surgery: results from a randomized study. Circulation. 2001;104:1761-6.

12. Barbut D, Hinton RB, Szatrowski TP, Hartman GS, Bruefach M, Williams-Russo $\mathrm{P}$, et al. Cerebral emboli detected during bypass surgery are associated with clamp removal. Stroke. 1994;25:2398-402.

13. Calafiore AM, Di Mauro M, Teodori G, Di Giammarco G, Cirmeni S, Contini M, et al. Impact of aortic manipulation on incidence of cerebrovascular accidents after surgical myocardial revascularization. Ann Thorac Surg. 2002;73:1387-93.

14. Patel NC, Pullan DM, Fabri BM. Does off-pump total arterial revascularization without aortic manipulation influence neurological outcome? A study of 226 consecutive, unselected cases. Heart Surg Forum. 2002;5:28-32.

15. Mills NL, Everson CT. Atherosclerosis of the ascending aorta and coronary artery bypass. J Thorac Cardiovasc Surg. 1991;102:546-53.

16. Lev-Ran O, Paz Y, Pevni D, Kramer A, Shapira I, Locker C, et al. Bilateral internal thoracic artery grafting: midterm results of composite versus in-situ crossover graft. Ann Thorac Surg. 2002;74:704-11.

17. Arom KV, Flavin T, Emery RW, Kshettry VR, Janey PA, Peterson RJ. Safety and efficacy of off-pump coronary artery bypass grafting. Ann Thorac Surg. 2000;69;704-10.

18. Demaria RG, Carrier M, Fortier S, Martineau R, Fortier A, Cartier R, et al. Reduced mortality and strokes with off-pump coronary artery bypass grafting surgery in octogenarians. Circulation. 2002;106(12 Suppl 1):I5-10.

19. Yokoyama R, Baumgartner FJ, Gheissari A, Capouya ER, Panagiotides GP, Declusin RJ. Off-pump versus on-pump coronary bypass in high-risk patients. Ann Thorac Surg. 2000;70:1546-50.

20. Leacche M, Carrier M, Bouchard D, Pellerin M, Perrault LP, Paga P, et al. Improving neurologic outcome in off-pump coronary surgery: the no-touch technique. Heart Forum. 2003;6:169-75.

21. Kobayashi S, Sasako Y, Bando K, Niwaya K, Tagusari O, Nakajima $\mathrm{H}$, et al. Multiple off-pump coronary revascularization with "aorta no-touch" technique using composite sequential methods. Heart Surg Forum. 2002;5:114-8.

22. Rorich MB, Furlan AJ. Risk at cardiac surgery in patients with prior stroke. Neurology. 1990;40:835-7.

23. Stamou SC, Hill PC, Dangas G, Pfister AJ, Boyce SW, Dullum MK, et al. Stroke after coronary artery bypass: incidence, predictors and clinical outcome. Stroke. 2001;32:1508-13. 
24. Strandgaard S. Hypertension and stroke. J Hypertens Suppl. 1996;14: S23-7.

25. Wareing TH, Davila-Roman VG, Barzilai B, Murphy SF, Kouchoukos NT. Management of severely atherosclerotic ascending aorta during cardiac operations. J Thorac Cardiovasc Surg. 1992;103:453-62.

26. Wilson MG, Boyd SY, Lisagor PG, Rubal BJ, Cohen DJ. Ascending aortic atheroma assessed intraoperatively by epiaortic and transesophageal echocardiography. Ann Thorac Surg. 2000;70:25-30.

27. Shimokawa T, Minato N, Yamada N, Takeda Y, Hisamatsu Y, Itoh M. Assessment of ascending aorta using epiaortic ultrasonography during off-pump coronary artery bypass grafting. Ann Thorac Surg. 2002;74: 2097-100.
28. Eckstein FS, Bonilla LF, Englberger L, Immer FF, Berg TA, Schmidli $\mathrm{J}$, et al. The St Jude Medical symmetry aortic connector system for proximal vein graft anastomoses in coronary artery bypass grafting. J Thorac Cardiovasc Surg. 2002;123:778-82.

29. Van Boven WG, Berry G, International Council of Emboli Management (ICEM) Study Group. Intraaortic filtration captures particulate debris in OPCAB cases using anastomotic devices. Heart Surg Forum. 2002;5 Suppl 4:S461-7.

30. Katariya K, Yassin S, Tehrani HY, Lombardi P, Marsoor S, Salerno TA. Initial experience with sutureless proximal anastomoses performed with mechanical connector leading to clampless off-pump coronary artery bypass surgery. Ann Thorac Surg. 2004;77:563-8.

Access to The Journal of Thoracic and Cardiovascular Surgery Online is reserved for print subscribers!

Full-text access to The Journal of Thoracic and Cardiovascular Surgery Online is available for all print subscribers. To activate your individual online subscription, please visit The Journal of Thoracic and Cardiovascular Surgery Online, point your browser to http://www.mosby.com/jtcvs, follow the prompts to activate your online access, and follow the instructions. To activate your account, you will need your subscriber account number, which you can find on your mailing label (note: the number of digits in your subscriber account number varies from 6 to 10). See the example below in which the subscriber account number has been circled:

\section{Sample mailing label}

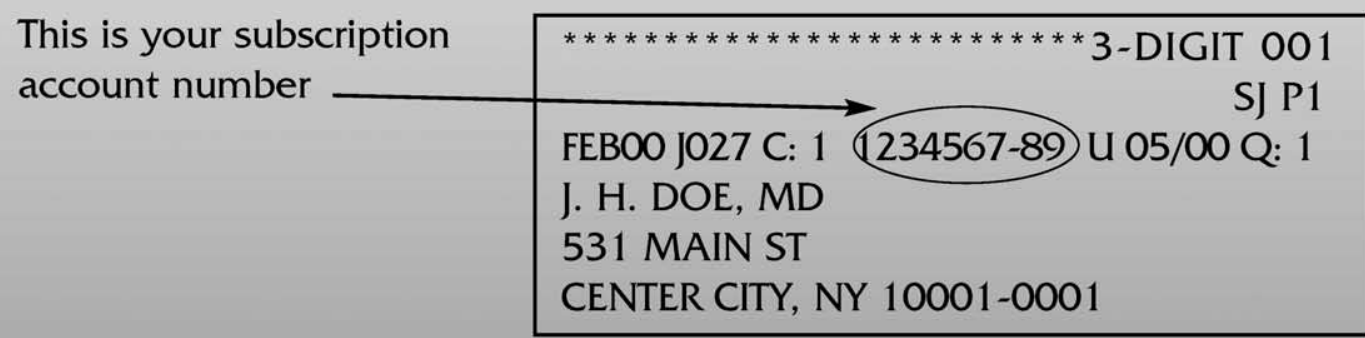

Personal subscriptions to The Journal of Thoracic and Cardiovascular Surgery Online are for individual use only and may not be transferred. Use of The Journal of Thoracic and Cardiovascular Surgery Online is subject to agreement to the terms and conditions as indicated online. 